\title{
Interactions between PPAR Gamma and the Canonical Wnt/Beta-Catenin Pathway in Type 2 Diabetes and Colon Cancer
}

\author{
Yves Lecarpentier, ${ }^{1}$ Victor Claes, ${ }^{2}$ Alexandre Vallée, ${ }^{3,4}$ and Jean-Louis Hébert ${ }^{5}$ \\ ${ }^{1}$ Centre de Recherche Clinique, Hôpital de Meaux, Meaux, France \\ ${ }^{2}$ Department of Pharmaceutical Sciences, University of Antwerp, Wilrijk, Belgium \\ ${ }^{3} \mathrm{CHU}$ Amiens Picardie, Université Picardie Jules Verne, Amiens, France \\ ${ }^{4}$ Experimental and Clinical Neurosciences Laboratory, INSERM U1084, University of Poitiers, France \\ ${ }^{5}$ Institut de Cardiologie, Hôpital de la Pitié-Salpêtrière, Assistance Publique-Hôpitaux de Paris, Paris, France \\ Correspondence should be addressed to Yves Lecarpentier; yves.c.lecarpentier@gmail.com
}

Received 13 July 2016; Revised 22 October 2016; Accepted 22 January 2017; Published 19 February 2017

Academic Editor: Richard P. Phipps

Copyright (C) 2017 Yves Lecarpentier et al. This is an open access article distributed under the Creative Commons Attribution License, which permits unrestricted use, distribution, and reproduction in any medium, provided the original work is properly cited.

\begin{abstract}
In both colon cancer and type 2 diabetes, metabolic changes induced by upregulation of the Wnt/beta-catenin signaling and downregulation of peroxisome proliferator-activated receptor gamma (PPAR gamma) may help account for the frequent association of these two diseases. In both diseases, PPAR gamma is downregulated while the canonical Wnt/beta-catenin pathway is upregulated. In colon cancer, upregulation of the canonical Wnt system induces activation of pyruvate dehydrogenase kinase and deactivation of the pyruvate dehydrogenase complex. As a result, a large part of cytosolic pyruvate is converted into lactate through activation of lactate dehydrogenase. Lactate is extruded out of the cell by means of activation of monocarboxylate lactate transporter-1. This phenomenon is called Warburg effect. PPAR gamma agonists induce beta-catenin inhibition, while inhibition of the canonical Wnt/beta-catenin pathway activates PPAR gamma.
\end{abstract}

\section{Introduction}

In numerous mammalian living cells, PPAR gamma and the canonical Wnt/beta-catenin pathway behave in an opposite manner [1-5]. Beta-catenin and PPAR gamma interact with each other in a mechanism that alters each of their activities [6]. In several diseases, PPAR gamma is upregulated while canonical Wnt/beta-catenin is downregulated [7] such as in arrhythmogenic right ventricular cardiomyopathy (ARVC), osteoporosis, and certain neurodegenerative diseases (Alzheimer's disease [8], bipolar disorder, and schizophrenia). Conversely, in other diseases, PPAR gamma is downregulated while canonical Wnt/beta-catenin is upregulated such as in type 2 diabetes, cancers, and certain neurodegenerative diseases (amyotrophic lateral sclerosis [9], Parkinson's disease, Huntington's disease, multiple sclerosis, and Friedreich's ataxia). PPAR gamma agonists induce betacatenin inhibition in several cellular systems $[1,3,4,10]$.
Moreover, inhibition of canonical Wnt/beta-catenin pathway induces activation of PPAR gamma [11-13]. Nonsteroidal anti-inflammatory drug inhibition of beta-catenin in malignant cells requires a high level expression of PPAR gamma and its coreceptor retinoid-X-receptor alpha [14]. In terms of PPAR gamma and Wnt/beta-catenin signaling, both type 2 diabetes and colon cancer share several similarities from a metabolic point of view. In the two diseases, upregulation of the canonical Wnt system leads to activation of pyruvate dehydrogenase kinase (PDK), which decreases the activity of the pyruvate dehydrogenase complex (PDH). Thus, pyruvate cannot be totally converted into acetyl-coenzyme which does not the mitochondrial TCA cycle. Conversely, PPAR gamma activation selectively decreased PDK mRNA [15]. The multiple and complex properties of these two major pathways, particularly in glucose regulation and cell proliferation, may partly account for the association frequently observed between type 2 diabetes and colon cancer. 


\section{Link between Type 2 Diabetes and Colon Cancer}

The association between type 2 diabetes and cancer, including pancreatic and endometrial carcinoma, breast cancer, and colorectal and bladder cancers, has been known for many years. Epidemiological studies have reported a link between type 2 diabetes, obesity, and cancer, especially colon cancer [16-19]. Type 2 diabetes associated with obesity represents a major risk factor for cancer [20-24]. Shared risk factors for colorectal cancer and type 2 diabetes include obesity, physical inactivity, and ageing. Patients with type 2 diabetes present a $30-40 \%$ higher risk of developing colon cancer compared to those without diabetes. Type 2 diabetes risk variants also contribute to the risk of colorectal cancer [25]. Metformin, an antidiabetic agent, decreases cancer mortality in diabetic patients [26].

\section{Underlying Molecular Basis for the Link between Diabetes and Colon Cancer}

The underlying molecular basis for the link between type 2 diabetes and colon cancer is not fully understood. Hyperinsulinemia provides a link between diabetes, obesity, and cancer. Hyperinsulinemia and/or insulin resistance represent major factors in cancer pathogenesis [27]. The hypothesis for the association between diabetes and cancer is based on the fact that, in type 2 diabetes, hyperinsulinemia promotes the growth of cancer cells [28]. In colon cancer, the hyperinsulinemia hypothesis suggests that elevated levels of both insulin and free insulin growth factor (IGF-1) promote cell proliferation and enhancement of cell transformation, ultimately resulting in colorectal cancer [29]. High insulin levels represent an adaptive process to insulin resistance at the onset of type 2 diabetes. Cancers overexpress receptors for insulin, including insulin receptor A and IGF-1 receptor. Increased insulin/IGF signaling favors the proliferative properties of the two hormones. Moreover, hyperglycemia and chronic inflammation may also play a role in promoting cancer growth [30].

\section{Activation of Canonical Wnt Signaling Induces Aerobic Glycolysis or Warburg Effect}

4.1. Canonical Wnt/Beta-Catenin Pathway (Figures 1 and 2). The Wnt/beta-catenin signaling plays an important role in cell fate, epithelial-mesenchymal transition (EMT) signaling, and embryonic development. Its dysfunction is involved in several pathologies such as carcinogenesis [31-34]. The major effector of the canonical Wnt pathway is the transcription factor beta-catenin/T-cell factor/lymphoid enhancer factor (TCF/LEF). In the absence of Wnt, the free cytosolic betacatenin is phosphorylated and is tightly controlled by a destruction complex, consisting of AXIN, tumor suppressor adenomatous polyposis coli (APC), and glycogen synthase kinase-3 (GSK-3beta). The destruction complex interacts with beta-catenin and phosphorylates it. The phosphorylated beta-catenin is then degraded in the proteasome (betacatenin proteasomal degradation: CPD). In the presence of ligands, the Wnt receptor interacts with the Frizzled (Fzd) receptor and LDL receptor-related protein 5/6 (LRP5/6) coreceptors. The Wnt receptor associates with Dishevelled protein (Dsh). This triggers the disruption of the destruction complex and prevents CPD. Beta-catenin then translocates to the nucleus and interacts with TCF/LEF which stimulates the beta-catenin downstream target genes (PDK, MTC-1, cMyc, cyclin D1, Cox 2, AXIN 2, etc.) [35-38] (Figures 1 and 2).

4.2. Canonical Wnt Pathway and Glucose. Importantly, glucose itself can directly impact the canonical Wnt pathway [39]. In cancer cells, glucose-induced beta-catenin acetylation favors the Wnt pathway. High glucose level enhances the nuclear translocation of beta-catenin in response to Wnt signaling. Increased glucose consumption is characteristic of cancer cells and high serum glucose levels may modulate cancer-related signaling.

4.3. Aerobic Glycolysis in Cancer Cells: The Warburg Effect. The role of the Wnt pathway in driving cell proliferation during oncogenesis and especially colon cancer is well-known [40]. On the one hand, overactivation of canonical Wnt/betacatenin signaling via TCF/LEF leads to cell proliferation, migration, angiogenesis, and EMT signaling [41-43]. On the other hand, the Wnt pathway induces aerobic glycolysis allowing glucose utilization for cancer cell proliferation [38, 44]. In cancer cells, a large proportion of the glucose supply is fermented in lactate regardless of the availability of oxygen. This phenomenon is called aerobic glycolysis or Warburg effect [45] and ultimately leads to anabolic production of biomass, that is, nucleotide synthesis $[46,47]$. As a consequence, in the Warburg effect, a large part of cytosolic pyruvate is not converted into acetyl-CoA which does not enter the TCA cycle. PDK1, a key regulator of glycolysis, phosphorylates the PDH complex which partially inhibits the conversion of pyruvate to acetyl-CoA into mitochondria [48]. PDK1 is upregulated in colon cancer [38]. Thus, cytosolic pyruvate is converted into lactate through activation of $\mathrm{LDH}$ A. Moreover, upregulation of MCT-1 diverts pyruvate towards lactate secretion from the cell. Aerobically derived lactate stimulates angiogenesis [49]. Thus, most of the cytosolic pyruvate is converted into lactate, which is secreted from the cell, and not oxidized in the mitochondrial TCA cycle, despite the availability of oxygen.

In colon cancer, it has recently been shown that activation of the canonical Wnt/beta-catenin pathway partly decreases the oxidative metabolism in the TCA cycle and promotes cell proliferation [38]. Both PDK1 and the lactate transporter MCT-1 are Wnt/beta-catenin targets and are overexpressed in cancer cells. Moreover, the Wnt pathway induces the transcription of genes involved in cell proliferation, that is, cMyc (through glutaminolysis, nucleotide synthesis, and LDH-A activation) and cyclin D1 (through G1) [50-55]. The Wnt target gene cMyc drives aerobic glycolysis and glutaminolysis $[52,54,56]$. Myc also induces LDH-A activation (for conversion of cytosolic pyruvate into lactate). cMyc 


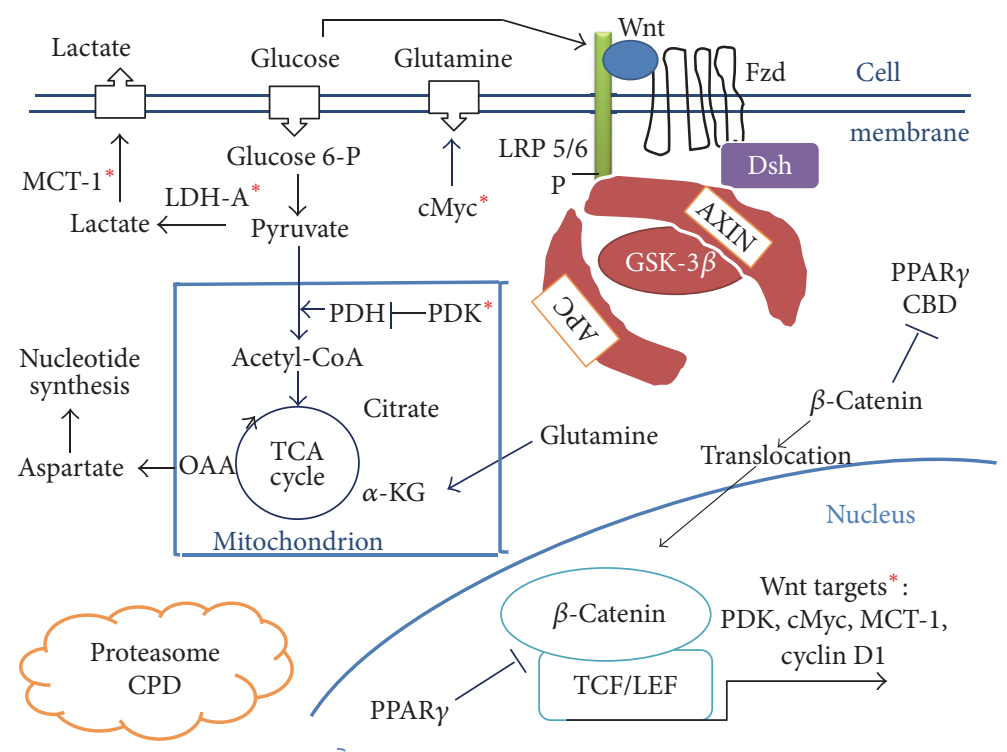

FIGURE 1: A model of interactions between the canonical Wnt/beta-catenin pathway and PPAR gamma under aerobic glycolysis conditions in colon cancer. In the absence of the Wnt ligand ("off state"), cytosolic beta-catenin is phosphorylated by GSK-3 beta. APS and AXIN combine with GSK-3 beta and beta-catenin to enhance the destruction process in the proteasome (beta-catenin proteasomal degradation: CPD). In the presence of the Wnt ligand ("on state"), Wnt binds both Frizzled and LRP5/6 receptors to initiate LRP phosphorylation and dishevelledmediated Frizzled internalization. This leads to dissociation of the AXIN/APC/GSK-3 beta complex. Beta-catenin phosphorylation is inhibited. Thus, beta-catenin accumulates in the cytosol and then translocates to the nucleus to bind TCF-LEF cotranscription factors, which induce the Wnt-response gene transcription (PDK, MCT-1, cMyc, and cyclin D1). Glucose itself activates the Wnt pathway. PPAR gamma via APC activates CPD. PPAR gamma inhibits the beta-catenin-TCF/LEF complex. Beta-catenin binds PPAR gamma CBD. PDK inhibits the PDH complex in mitochondria. Thus pyruvate cannot be converted into acetyl-CoA and enters the TCA cycle. Myc activates LDH-A which converts cytosolic pyruvate into lactate. MCT-1 favors lactate secretion from the cytosol which favors angiogenesis. cMyc increases glutamine entry in the cytosol and mitochondria. Myc-induced glutamine enhances nucleotide synthesis. Abbreviations are as follows: adenomatous polyposis coli (APC); alpha ceto-glutarate (a-KG); beta-catenin proteasomal degradation: CPD; catenin binding domain (CBD); Dishevelled (Dsh); Frizzled (Fzd); glycogen synthase kinase-3beta (GSK-3beta); lactate dehydrogenase (LDH); low-density lipoprotein receptor-related protein 5/6 (LRP5/6); monocarboxylate lactate transporter-1 (MCT-1); peroxisome proliferator-activated receptor gamma (PPAR gamma); pyruvate dehydrogenase complex (PDH); pyruvate dehydrogenase kinase (PDK); T-cell factor/lymphoid enhancer factor (TCF/LEF); tricarboxylic acid (TCA); *: Wnt targets: PDK, cMyc, MCT-1, and cyclin D1.

induces glutamine uptake into the cell and the mitochondria and favors aspartate synthesis [52] (Figures 1 and 2). Through the Warburg effect, cMyc-induced glutaminolysis favors nucleotide synthesis. cMyc also increases the hypoxiainducible factor-1 alpha- (HIF-lalpha-) mediated control of PDK1 [57].

Thus, in colon cancer, activation of canonical Wnt signaling directly acts on aerobic glycolysis and increases vessel development via the Wnt target gene PDK1 [38]. Part of the pyruvate is converted into acetyl-CoA which enters the TCA cycle and is converted into citrate, which promotes protein synthesis. Cellular accumulation of metabolic intermediates (aspartate, serine, glycine, and ribose) allows de novo nucleotide synthesis, which contributes to growth and proliferation (Figure 1). Moreover, blocking Wnt reduces PDK1 levels via the transcription regulation and reduces in vivo tumor growth. PDK1 is upregulated in several cancers, especially colon cancer [58-60]. Likewise, PDK1 and PDK2 enhance angiogenesis $[61,62]$. PDK1 favors vascularization [38]. Angiogenesis is also favored by lactates [63]. MCTs are also upregulated in colon cancer [64].

\section{Pyruvate Dehydrogenase Kinases (PDKs) and Diseases}

Metabolic disorders combined with abnormal PDK activity are often associated with numerous diseases, such as type 2 diabetes, obesity, metabolic disorders, cardiomyopathies, neuropathies, and several types of cancer. PDKs play a key role in metabolic flexibility [65]. They are transcriptionally regulated by insulin, glucocorticoids, thyroid hormone, and fatty acids and play an important role in diabetes and obesity [66]. In type 2 diabetes, the two isoforms PDK2 and PDK4 are induced in a tissue-specific manner. Transcriptional upregulation of PDKs [67-69] decreases the PDH activity in several metabolic disorders, such as diabetes [70-72]. In type 2 diabetes, decreased levels of insulin promote an increase in both PDK4 gene expression and PDK2 mRNA levels. PDK2 and PDK4 mRNAs are upregulated in response to glucose deprivation and fatty acid supplementation. This is reversed by insulin treatment as insulin directly downregulates PDK2 and PDK4 mRNA transcripts [15]. 


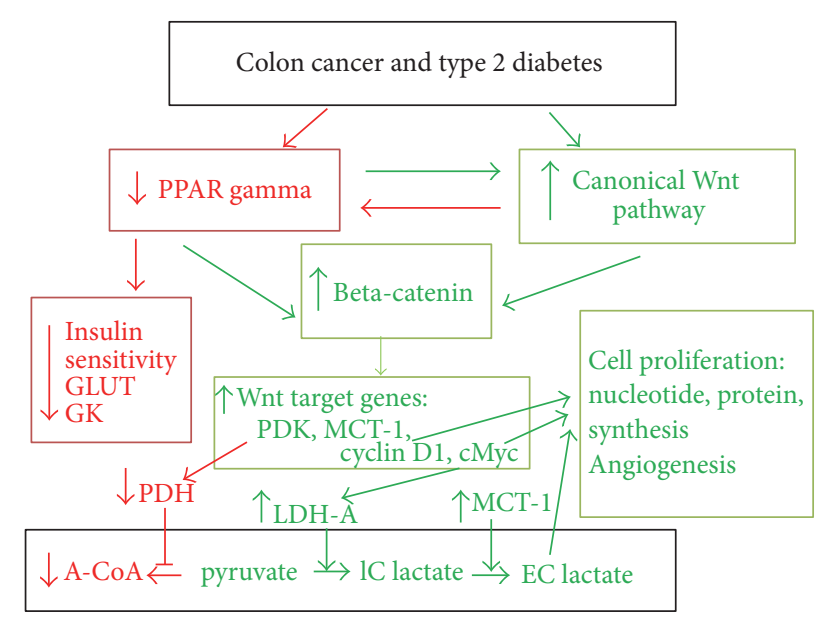

FIGURE 2: A schematic representation of interactions between PPAR gamma and the canonical Wnt/beta-catenin pathway in type 2 diabetes and colon cancer. Green arrow: activation; red arrow: inhibition; abbreviations are as follows: acetyl-CoA (A-CoA); glucokinase (GK); glucose transporter (GLUT); intracellular lactate (IC lactate); extracellular lactate (EC lactate); lactate dehydrogenaseA (LDH-A); monocarboxylate lactate transporter-1 (MCT-1); pyruvate dehydrogenase (PDH); pyruvate dehydrogenase kinase (PDK); peroxisome proliferator-activated receptor gamma (PPAR gamma).

\section{Interactions between PPAR Gamma and the Canonical Wnt/Beta-Catenin Pathway}

6.1. PPAR Gamma (Figures 1 and 2). PPAR alpha, beta/delta, and gamma are ligand-activated transcriptional factors which belong to the nuclear hormone receptor superfamily. PPARs heterodimerize with the retinoid X receptor (RXR). PPAR gamma is expressed in various cell types, such as adipose tissues, muscles, brain, and immune cells. PPAR gamma is involved in the expression of many genes and contributes to glucose homeostasis, insulin sensitivity, lipid metabolism, immune responses, inflammation, and cell fate [73-75]. The net result of the pleiotropic effects of thiazolidinediones (TZDs), a class of PPAR gamma agonists, is improvement of insulin sensitivity [76] in peripheral tissues together with an increase in the glucose-sensing ability of pancreatic betacells in diabetic subjects. They improve glucose tolerance and insulin sensitivity in type 2 diabetic patients and in animal models of insulin resistance [77, 78]. Enhanced insulin sensitivity improves peripheral glucose disposal, which decreases the demand for insulin secretion from beta-cells and hepatic glucose production. Effects of TZDs result in increased peripheral glucose use, reduced hepatic glucose output, and, consequently, improvement in overall glycemic control. They act on the promoters of GLUT2 and beta-glucokinase (GK) in pancreatic beta-cells and liver. In adipose tissue, several genes are under the transcriptional control of PPAR gamma, including lipoprotein lipase, acyl-CoA synthetase, fatty acid translocase, and fatty acid transport protein [75]. Dysfunction of PPAR gamma is implied in numerous pathological states such as diabetes, obesity, cancers, and atherosclerosis.
TZDs directly activate PPAR gamma and are insulin sensitizing drugs. Some TZDs have been used for treating type 2 diabetes. PPAR gamma also regulates circadian cardiovascular rhythms of blood pressure and heart rate by means of BMAL1 [79, 80]. In cultured muscle cells, PPAR alpha and delta agonists specifically upregulate the expression of PDK4 mRNA, whereas PPAR gamma activation selectively decreases PDK2 mRNA [15]. The PPAR alpha agonist WY14,643 increases PDK4 mRNA levels in Morris hepatoma $7800 \mathrm{Cl}$ cells [67]. In the diabetic heart, PPAR alpha activity and its downstream targets are upregulated, which leads to a dramatic increase in both fatty acid uptake and oxidation [81] and decreases the mitochondrial pyruvate degradation by upregulating PDK2 and 4 .

6.2. PPAR Gamma Agonists Induce Beta-Catenin Inhibition in Several Cellular Systems. The functional crosstalk between PPAR gamma and the canonical Wnt/beta-catenin signaling involves the TCF/LEF binding domain of beta-catenin and a catenin binding domain (CBD) within PPAR gamma. In cells that express an APC-containing destruction complex, activation of PPAR gamma induces CPD (Figure 1). TZDs induce a reduction in the cytoplasmic level of beta-catenin in both adipocytes [1] and hepatocytes [3]. PPAR gamma inhibits osteoblastogenesis, promotes adipogenesis, and suppresses the Wnt/beta-catenin pathway during adipogenesis $[4,10]$. Conversely Wnt/beta-catenin signaling activation inhibits PPAR gamma and leads to osteogenesis [4].

6.3. Inhibition of Canonical Wnt/Beta-Catenin Pathway Induces Activation of PPAR Gamma in Several Cellular Systems. Inhibition of Wnt/beta-catenin signaling and upregulation of PPAR gamma have been reported in ARVC $[12,13]$. Gamma-catenin presents structural similarities with betacatenin [31]. In transgenic mice, gamma-catenin translocates to the nucleus, competes with beta-catenin, and inhibits the canonical Wnt/beta-catenin signaling through the TCF/LEF transcription factors $[82,83]$. This results in enhancing adipogenesis, thus summarizing the phenotype of the human ARVC [11-13].

6.4. Inactivation of PPAR Gamma and Activation of the Wnt/Beta-Catenin Pathway in Colon Cancer. Beta-cateninTCF/LEF signaling is activated in colon cancer [84]. Nuclear accumulation of beta-catenin, a marker of poor prognosis, drives cancer cell proliferation. Activation of Wnt signaling can occur via $A P C$ gene mutations and this enables development of colon cancer [85]. In colon cancer cells, activation of the Wnt/beta-catenin pathway decreases PPAR gamma activity [86]. Beta-catenin can also interact with RXR alpha. In $A P C$ - and p53-mutated colorectal cancer cells, RXR agonists inactivate beta-catenin via RXR alpha. RXR alphamediated inactivation of oncogenic beta-catenin occurs in parallel with a reduction in cell proliferation [87]. Mutations in PPAR gamma are linked with human colon cancer [88]. In normal untransformed cells, PPAR gamma induces CPD through both the CBD of PPAR gamma and the TCF binding domain of beta-catenin (Figure 1). In transformed cells, 
there is no oncogenic beta-catenin degradation. In colon carcinogenesis, PPAR gamma can suppress tumorigenesis by downregulating the oncogene beta-catenin [89]. An early treatment by means of PPAR gamma agonists, and before the onset of carcinogenesis, might prevent tumor development. In many cell types, PPAR gamma agonists induce antitumorigenic effects, probably due to their antiproliferative and prodifferentiation effects. Troglitazone inhibits development of tumors that are derived from colon cancer cells [90]. In transplantable tumors derived from human colon cancer cells, troglitazone induces a significant reduction of growth. Troglitazone fed to rodents decreases the formation of aberrant crypt foci, which is an early stage in the development of colon carcinoma [91]. Activation of PPAR gamma induces CPD in cells that express an APC-containing destruction complex although the oncogenic beta-catenin inhibits the expression of PPAR gamma target genes [6]. Mutations in the TCF/LEF binding domain of an oncogenic beta-catenin leads to both decreased interaction with PPAR gamma and inhibition of PPAR gamma activity [6]. Conversely, in some cases, PPAR gamma activation induces deleterious procarcinogenic effects. Thus, in APC Min mice, used as a model for human familial adenomatous polyposis, TZDs increase the number of colon tumors $[92,93]$. Numerous studies on cancer and PPAR gamma have focused on the potential for employing PPAR gamma agonists in cancer treatment. As a monotherapy, PPAR gamma agonists have induced little success in clinical trials. Results have been shown promise with combined treatments in culture and animal models. A role for PPAR gamma as a tumor suppressor and inducer of differentiation of cancer stem cells has also been investigated. Various conclusions concerning the prevalence of PPAR gamma mutations in cancer have been observed [94].

6.5. Inactivation of PPAR Gamma and Activation of the Wnt/Beta-Catenin Pathway in Type 2 Diabetes. TZDs are potent insulin-sensitizers and certain TZDs represent a therapeutic target for the treatment of type 2 diabetes. However, the involvement of PPAR gamma in numerous pathways generates negative side-effects after PPAR gamma activation by TZDs in tissues or cells not concerned by the disease [95]. PPAR gamma enables activation of GLUT2 and GK in liver and beta-cells and contributes to the beneficial effects induced by TZDs, which improve glucose homeostasis in type 2 diabetic patients. Moreover, dominant-negative mutation in the PPAR gamma gene is associated with severe hyperglycemia in patients. This provides a genetic link between PPAR gamma and type 2 diabetes [96]. Humans with dominant-negative mutations in PPAR gamma manifest partial lipodystrophy and severe peripheral and hepatic insulin resistance [97]. Expression of TNF-alpha, which induces insulin resistance, is reduced by PPAR gamma ligands, suggesting that the insulin-sensitizing effect of TZDs is related to its anti-inflammatory properties [98]. PPAR gamma has a significantly lower expression in obese type 2 diabetics than in nondiabetic obese subjects [99].

The Wnt/beta-catenin signaling pathway is involved in diabetes mellitus [100]. Wnt signaling and TCF7L2 are negative regulators of hepatic gluconeogenesis, and TCF7L2 belongs to the downstream effectors of insulin in hepatocytes [101]. Wnt/beta-catenin may represent a link between diabetes and cancer, due to the strong genetic association between specific polymorphisms in the TCF7L2 (TCF4) gene and diabetes $[102,103]$. TCF7L2 polymorphisms enhance the risk of developing type 2 diabetes [104-106]. Mutations in LRP5 lead to the development of diabetes and obesity [107]. The Wnt pathway is involved in glucose-induced insulin secretion [108] and production of the incretin hormone glucagon-like peptide-1 [109-111]. Polymorphisms in Wnt5B are associated with a higher risk of developing type 2 diabetes [112]. Otherwise, the human LRP5 gene maps within the IDDM4 region on chromosome 11q13 [113, 114]. Conversely, TCF7L2 knockdown increases human pancreatic beta-cell apoptosis and reduces beta-cell proliferation and glucosestimulated insulin secretion [115].

\section{Conclusions}

PPAR gamma is downregulated while the canonical Wnt/ beta-catenin pathway is upregulated in both type 2 diabetes and colon cancer. Wnt activates some crucial metabolic key enzymes, such as PDKs in the two pathologies. In colon cancer, this leads to aerobic glycolysis or the Warburg effect. Decreased PDH activity by upregulated PDK modifies metabolic flexibility that is, the capacity of the cell to adjust glucose and fatty acid oxidation. Competition between glucose and fatty acids for oxidation occurs at the level of the PDH complex, whose activity is decreased by PDKs. In colon cancer, partial deviation of pyruvate toward lactate contributes to protein synthesis, which are required for cell growth and proliferation. These major metabolic alterations induced by upregulated Wnt/beta-catenin signaling and downregulated PPAR gamma may partly account for the frequently encountered association between type 2 diabetes and colon cancer.

\section{Abbreviations}

APC: $\quad$ Adenomatous polyposis coli

ARVC: Arrhythmogenic right ventricular

dysplasia/cardiomyopathy

CPD: Beta-catenin proteasomal

CBD: $\quad$ Catenin binding domain

Dsh: Dishevelled

EMT: $\quad$ Epithelial-mesenchymal transition

Fzd: $\quad$ Frizzled

GK: $\quad$ Glucokinase

GLUT: $\quad$ Glucose transporter

GSK-3beta: Glycogen synthase kinase-3beta

IGF-1: Insulin growth factor

LDH-A: Lactate dehydrogenase-A

LRP5/6: LDL receptor-related protein 5/6 coreceptors

LRP5/6: Low-density lipoprotein receptor-related protein $5 / 6$

MCT-1: Monocarboxylate lactate transporter-1 
PPAR gamma: Peroxisome proliferator-activated receptor gamma

PGC-1 alpha: Peroxisome proliferator-activated receptorgamma coactivator-1 alpha

PDH: $\quad$ Pyruvate dehydrogenase

PDK: $\quad$ Pyruvate dehydrogenase kinase

RXR Alpha: Retinoid X receptor alpha

TCF/LEF: T-cell factor/lymphoid enhancer factor

TZD:

TCA: Thiazolidinedione

Tricarboxylic acid.

\section{Competing Interests}

The authors declare no conflict of interests.

\section{Authors' Contributions}

Yves Lecarpentier, Victor Claes, Alexandre Vallée, and JeanLouis Hébert have equally contributed to this review.

\section{Acknowledgments}

The authors would like to thank Dr Christophe Locher, Director of the Clinical Research Center, Meaux Hospital, and Mr Vincent Gobert, Administrative Manager of the Clinical Research Center, Meaux Hospital, Meaux, France, for their valuable support in making the necessary research facilities available for this study. The manuscript has been revised by Brian Keogh, PhD.

\section{References}

[1] D. L. Gerhold, F. Liu, G. Jiang et al., "Gene expression profile of adipocyte differentiation and its regulation by peroxisome proliferator-activated receptor- $\gamma$ agonists," Endocrinology, vol. 143, no. 6, pp. 2106-2118, 2002.

[2] G. D. Girnun, F. E. Domann, S. A. Moore, and M. E. C. Robbins, "Identification of a functional peroxisome proliferatoractivated receptor response element in the rat catalase promoter," Molecular Endocrinology, vol. 16, no. 12, pp. 2793-2801, 2002.

[3] C. Sharma, A. Pradeep, L. Wong, A. Rana, and B. Rana, "Peroxisome proliferator-activated receptor $\gamma$ activation can regulate $\beta$-catenin levels via a proteasome-mediated and adenomatous polyposis coli-independent pathway," The Journal of Biological Chemistry, vol. 279, no. 34, pp. 35583-35594, 2004.

[4] I. Takada, A. P. Kouzmenko, and S. Kato, "Wnt and PPAR $\gamma$ signaling in osteoblastogenesis and adipogenesis," Nature Reviews Rheumatology, vol. 5, no. 8, pp. 442-447, 2009.

[5] D. Lu and D. A. Carson, "Repression of $\beta$-catenin signaling by PPAR $\gamma$ ligands," European Journal of Pharmacology, vol. 636, no. 1-3, pp. 198-202, 2010.

[6] J. Liu, H. Wang, Y. Zuo, and S. R. Farmer, "Functional interaction between peroxisome proliferator-activated receptor $\gamma$ and $\beta$-catenin," Molecular and Cellular Biology, vol. 26, no. 15, pp. 5827-5837, 2006.

[7] Y. Lecarpentier, V. Claes, G. Duthoit, and J.-L. Hébert, "Circadian rhythms, Wnt/beta-catenin pathway and PPAR alpha/gamma profiles in diseases with primary or secondary cardiac dysfunction," Frontiers in Physiology, vol. 5, article 429, 2014.

[8] A. Vallee and Y. Lecarpentier, "Alzheimer disease: crosstalk between the canonical Wnt/beta-catenin pathway and PPARs alpha and gamma," Frontiers in Neuroscience, vol. 10, article 459, 2016.

[9] Y. Lecarpentier and A. Vallée, "Opposite interplay between PPAR gamma and canonical Wnt/beta-catenin pathway in amyotrophic lateral sclerosis," Frontiers in Neurology, vol. 7, article no. 100, 2016.

[10] M. Moldes, Y. Zuo, R. F. Morrison et al., "Peroxisomeproliferator-activated receptor $\gamma$ suppresses Wnt/ $\beta$-catenin signalling during adipogenesis," Biochemical Journal, vol. 376, no. 3, pp. 607-613, 2003.

[11] D. Corrado, C. Basso, G. Thiene et al., "Spectrum of clinicopathologic manifestations of arrhythmogenic right ventricular cardiomyopathy/dysplasia: a multicenter study," Journal of the American College of Cardiology, vol. 30, no. 6, pp. 1512-1520, 1997.

[12] E. Garcia-Gras, R. Lombardi, M. J. Giocondo et al., "Suppression of canonical $\mathrm{Wnt} / \beta$-catenin signaling by nuclear plakoglobin recapitulates phenotype of arrhythmogenic right ventricular cardiomyopathy," The Journal of Clinical Investigation, vol. 116, no. 7, pp. 2012-2021, 2006.

[13] F. Djouadi, Y. Lecarpentier, J.-L. Hébert, P. Charron, J. Bastin, and C. Coirault, "A potential link between peroxisome proliferator-activated receptor signalling and the pathogenesis of arrhythmogenic right ventricular cardiomyopathy," Cardiovascular Research, vol. 84, no. 1, pp. 83-90, 2009.

[14] D. Lu, H. B. Cottam, M. Corr, and D. A. Carson, "Repression of $\beta$-catenin function in malignant cells by nonsteroidal antiinflammatory drugs," Proceedings of the National Academy of Sciences of the United States of America, vol. 102, no. 51, pp. 18567-18571, 2005.

[15] E. L. Abbot, J. G. McCormack, C. Reynet, D. G. Hassall, K. W. Buchan, and S. J. Yeaman, "Diverging regulation of pyruvate dehydrogenase kinase isoform gene expression in cultured human muscle cells," FEBS Journal, vol. 272, no. 12, pp. 30043014, 2005.

[16] C. Gao and S.-K. Yao, "Diabetes mellitus: a 'true' independent risk factor for hepatocellular carcinoma?" Hepatobiliary and Pancreatic Diseases International, vol. 8, no. 5, pp. 465-473, 2009.

[17] M. Gerber, "Background review paper on total fat, fatty acid intake and cancers," Annals of Nutrition and Metabolism, vol. 55, no. 1-3, pp. 140-161, 2009.

[18] P. Hillon, B. Guiu, J. Vincent, and J.-M. Petit, “Obesity, type 2 diabetes and risk of digestive cancer," Gastroentérologie Clinique et Biologique, vol. 34, no. 10, pp. 529-533, 2010.

[19] M. J. Khandekar, P. Cohen, and B. M. Spiegelman, "Molecular mechanisms of cancer development in obesity," Nature Reviews Cancer, vol. 11, no. 12, pp. 886-895, 2011.

[20] A. G. Renehan, M. Tyson, M. Egger, R. F. Heller, and M. Zwahlen, "Body-mass index and incidence of cancer: a systematic review and meta-analysis of prospective observational studies," The Lancet, vol. 371, no. 9612, pp. 569-578, 2008.

[21] P. Vigneri, F. Frasca, L. Sciacca, G. Pandini, and R. Vigneri, "Diabetes and cancer," Endocrine-Related Cancer, vol. 16, no. 4, pp. 1103-1123, 2009.

[22] R. Vigneri, “Diabetes: diabetes therapy and cancer risk," Nature Reviews Endocrinology, vol. 5, no. 12, pp. 651-652, 2009. 
[23] E. Giovannucci, D. M. Harlan, M. C. Archer et al., "Diabetes and cancer: a consensus report," CA: A Cancer Journal for Clinicians, vol. 60, no. 4, pp. 207-221, 2010.

[24] P. J. H. L. Peeters, M. T. Bazelier, H. G. M. Leufkens, F. De Vries, and M. L. De Bruin, "The risk of colorectal cancer in patients with type 2 diabetes: associations with treatment stage and obesity," Diabetes Care, vol. 38, no. 3, pp. 495-502, 2015.

[25] I. Cheng, C. P. Caberto, A. Lum-Jones et al., "Type 2 diabetes risk variants and colorectal cancer risk: the multiethnic Cohort and PAGE studies," Gut, vol. 60, no. 12, pp. 1703-1711, 2011.

[26] R. J. O. Dowling, M. Zakikhani, I. G. Fantus, M. Pollak, and N. Sonenberg, "Metformin inhibits mammalian target of rapamycin-dependent translation initiation in breast cancer cells," Cancer Research, vol. 67, no. 22, pp. 10804-10812, 2007.

[27] E. Giovannucci, D. M. Harlan, M. C. Archer et al., "Diabetes and cancer: a consensus report," Diabetes Care, vol. 33, no. 7, pp. 1674-1685, 2010.

[28] P. Pisani, "Hyper-insulinaemia and cancer, meta-analyses of epidemiological studies," Archives of Physiology and Biochemistry, vol. 114, no. 1, pp. 63-70, 2008.

[29] J. M. Berster and B. Göke, "Type 2 diabetes mellitus as risk factor for colorectal cancer," Archives of Physiology and Biochemistry, vol. 114, no. 1, pp. 84-98, 2008.

[30] J. A. Johnson, B. Carstensen, D. Witte, S. L. Bowker, L. Lipscombe, and A. G. Renehan, "Diabetes and cancer (1): evaluating the temporal relationship between type 2 diabetes and cancer incidence," Diabetologia, vol. 55, no. 6, pp. 1607-1618, 2012.

[31] R. T. Moon, B. Bowerman, M. Boutros, and N. Perrimon, "The promise and perils of Wnt signaling through $\beta$-catenin," Science, vol. 296, no. 5573, pp. 1644-1646, 2002.

[32] R. T. Moon, A. D. Kohn, G. V. De Ferrari, and A. Kaykas, "WNT and $\boldsymbol{\beta}$-catenin signalling: diseases and therapies," Nature Reviews Genetics, vol. 5, no. 9, pp. 691-701, 2004.

[33] R. Nusse, "Wnt signaling in disease and in development," Cell Research, vol. 15, no. 1, pp. 28-32, 2005.

[34] H. Clevers, "Wnt/ $\beta$-catenin signaling in development and disease," Cell, vol. 127, no. 3, pp. 469-480, 2006.

[35] T.-C. He, A. B. Sparks, C. Rago et al., "Identification of c-MYC as a target of the APC pathway," Science, vol. 281, no. 5382, pp. 1509-1512, 1998.

[36] M. Shtutman, J. Zhurinsky, I. Simcha et al., "The cyclin D1 gene is a target of the $\beta$-catenin/LEF-1 pathway," Proceedings of the National Academy of Sciences of the United States of America, vol. 96, no. 10, pp. 5522-5527, 1999.

[37] S. Angers and R. T. Moon, "Proximal events in Wnt signal transduction," Nature Reviews Molecular Cell Biology, vol. 10, no. 7, pp. 468-477, 2009.

[38] K. T. Pate, C. Stringari, S. Sprowl-Tanio et al., "Wnt signaling directs a metabolic program of glycolysis and angiogenesis in colon cancer," The EMBO Journal, vol. 33, no. 13, pp. 1454-1473, 2014.

[39] A. Chocarro-Calvo, J. M. García-Martínez, S. Ardila-González, A. De la Vieja, and C. García-Jiménez, "Glucose-induced $\beta$ catenin acetylation enhances Wnt signaling in cancer," Molecular Cell, vol. 49, no. 3, pp. 474-486, 2013.

[40] M. Bienz and H. Clevers, "Linking colorectal cancer to Wnt signaling," Cell, vol. 103, no. 2, pp. 311-320, 2000.

[41] T. Brabletz, F. Hlubek, S. Spaderna et al., "Invasion and metastasis in colorectal cancer: epithelial-mesenchymal transition, mesenchymal-epithelial transition, stem cells and $\beta$-catenin," Cells Tissues Organs, vol. 179, no. 1-2, pp. 56-65, 2005.
[42] A. Klaus and W. Birchmeier, "Wnt signalling and its impact on development and cancer," Nature Reviews Cancer, vol. 8, no. 5, pp. 387-398, 2008.

[43] H. Clevers and R. Nusse, "Wnt/ $\beta$-catenin signaling and disease," Cell, vol. 149, no. 6, pp. 1192-1205, 2012.

[44] C. B. Thompson, "Wnt meets Warburg: another piece in the puzzle?” EMBO Journal, vol. 33, no. 13, pp. 1420-1422, 2014.

[45] O. Warburg, "On the origin of cancer cells," Science, vol. 123, no. 3191, pp. 309-314, 1956.

[46] R. J. DeBerardinis, J. J. Lum, G. Hatzivassiliou, and C. B. Thompson, "The biology of cancer: metabolic reprogramming fuels cell growth and proliferation," Cell Metabolism, vol. 7, no. 1, pp. 11-20, 2008.

[47] M. G. Vander Heiden, L. C. Cantley, and C. B. Thompson, "Understanding the warburg effect: the metabolic requirements of cell proliferation," Science, vol. 324, no. 5930, pp. 1029-1033, 2009.

[48] T. E. Roche, J. C. Baker, X. Yan et al., "Distinct regulatory properties of pyruvate dehydrogenase kinase and phosphatase isoforms," Progress in Nucleic Acid Research and Molecular Biology, vol. 70, pp. 33-75, 2001.

[49] T. K. Hunt, R. S. Aslam, S. Beckert et al., "Aerobically derived lactate stimulates revascularization and tissue repair via redox mechanisms," Antioxidants and Redox Signaling, vol. 9, no. 8, pp. 1115-1124, 2007.

[50] M. van de Wetering, E. Sancho, C. Verweij et al., "The $\beta$ catenin/TCF-4 complex imposes a crypt progenitor phenotype on colorectal cancer cells," Cell, vol. 111, no. 2, pp. 241-250, 2002.

[51] P. Chafey, L. Finzi, R. Boisgard et al., "Proteomic analysis of $\beta$ catenin activation in mouse liver by DIGE analysis identifies glucose metabolism as a new target of the Wnt pathway," Proteomics, vol. 9, no. 15, pp. 3889-3900, 2009.

[52] D. R. Wise, R. J. Deberardinis, A. Mancuso et al., "Myc regulates a transcriptional program that stimulates mitochondrial glutaminolysis and leads to glutamine addiction," Proceedings of the National Academy of Sciences of the United States of America, vol. 105, no. 48, pp. 18782-18787, 2008.

[53] R. Nusse, "Wnt signaling and stem cell control," Cell Research, vol. 18 , no. 5 , pp. 523-527, 2008.

[54] C. V. Dang, "Rethinking the warburg effect with Myc micromanaging glutamine metabolism," Cancer Research, vol. 70, no. 3, pp. 859-862, 2010.

[55] C. Niehrs and S. P. Acebron, "Mitotic and mitogenic Wnt signalling," EMBO Journal, vol. 31, no. 12, pp. 2705-2713, 2012.

[56] R. C. Osthus, H. Shim, S. Kim et al., "Deregulation of glucose transporter 1 and glycolytic gene expression by c-Myc," Journal of Biological Chemistry, vol. 275, no. 29, pp. 21797-21800, 2000.

[57] J.-W. Kim, P. Gao, Y.-C. Liu, G. L. Semenza, and C. V. Dang, "Hypoxia-inducible factor 1 and dysregulated c-Myc cooperatively induce vascular endothelial growth factor and metabolic switches hexokinase 2 and pyruvate dehydrogenase kinase 1," Molecular and Cellular Biology, vol. 27, no. 21, pp. 7381-7393, 2007.

[58] M. I. Koukourakis, A. Giatromanolaki, A. L. Harris, and E. Sivridis, "Comparison of metabolic pathways between cancer cells and stromal cells in colorectal carcinomas: a metabolic survival role for tumor-associated stroma," Cancer Research, vol. 66, no. 2, pp. 632-637, 2006.

[59] S. M. Wigfield, S. C. Winter, A. Giatromanolaki, J. Taylor, M. L. Koukourakis, and A. L. Harris, "PDK-1 regulates lactate production in hypoxia and is associated with poor prognosis in 
head and neck squamous cancer," British Journal of Cancer, vol. 98, no. 12, pp. 1975-1984, 2008.

[60] D. Baumunk, U. Reichelt, J. Hildebrandt et al., "Expression parameters of the metabolic pathway genes pyruvate dehydrogenase kinase-1 (PDK-1) and DJ-1/PARK7 in renal cell carcinoma (RCC)," World Journal of Urology, vol. 31, no. 5, pp. 1191-1196, 2013.

[61] T. McFate, A. Mohyeldin, H. Lu et al., "Pyruvate dehydrogenase complex activity controls metabolic and malignant phenotype in cancer cells," The Journal of Biological Chemistry, vol. 283, no. 33, pp. 22700-22708, 2008.

[62] G. Sutendra, P. Dromparis, A. Kinnaird et al., "Mitochondrial activation by inhibition of PDKII suppresses HIFla signaling and angiogenesis in cancer," Oncogene, vol. 32 , no. 13, pp. 16381650, 2013.

[63] H. Lu, R. A. Forbes, and A. Verma, "Hypoxia-inducible factor 1 activation by aerobic glycolysis implicates the Warburg effect in carcinogenesis," Journal of Biological Chemistry, vol. 277, no. 26, pp. 23111-23115, 2002.

[64] C. Pinheiro, A. Longatto-Filho, C. Scapulatempo et al., "Increased expression of monocarboxylate transporters 1, 2, and 4 in colorectal carcinomas," Virchows Archiv, vol. 452, no. 2, pp. 139-146, 2008.

[65] S. Zhang, M. W. Hulver, R. P. McMillan, M. A. Cline, and E. R. Gilbert, "The pivotal role of pyruvate dehydrogenase kinases in metabolic flexibility," Nutrition and Metabolism, vol. 11, article 10, 2014.

[66] I.-K. Lee, "The role of pyruvate dehydrogenase kinase in diabetes and obesity," Diabetes and Metabolism Journal, vol. 38, no. 3, pp. 181-186, 2014.

[67] B. Huang, P. Wu, M. M. Bowker-Kinley, and R. A. Harris, "Regulation of pyruvate dehydrogenase kinase expression by peroxisome proliferator-activated receptor- $\alpha$ ligands, glucocorticoids, and insulin," Diabetes, vol. 51, no. 2, pp. 276-283, 2002.

[68] H.-S. Kwon, B. Huang, T. G. Unterman, and R. A. Harris, "Protein kinase B- $\alpha$ inhibits human pyruvate dehydrogenase kinase4 gene induction by dexamethasone through inactivation of FOXO transcription factors," Diabetes, vol. 53, no. 4, pp. 899910, 2004.

[69] R. R. Attia, P. Sharma, R. C. Janssen et al., "Regulation of pyruvate dehydrogenase kinase 4 (PDK4) by CCAAT/enhancerbinding protein $\beta(\mathrm{C} / \mathrm{EBP} \beta)$," Journal of Biological Chemistry, vol. 286, no. 27, pp. 23799-23807, 2011.

[70] Y. I. Kim, F. N. Lee, W. S. Choi, S. Lee, and J. H. Youn, "Insulin regulation of skeletal muscle PDK4 mRNA expression is impaired in acute insulin-resistant states," Diabetes, vol. 55, no. 8, pp. 2311-2317, 2006.

[71] T. L. Pehleman, S. J. Peters, G. J. F. Heigenhauser, and L. L. Spriet, "Enzymatic regulation of glucose disposal in human skeletal muscle after a high-fat, low-carbohydrate diet," Journal of Applied Physiology, vol. 98, no. 1, pp. 100-107, 2005.

[72] S. J. Peters, R. A. Harris, P. Wu, T. L. Pehleman, G. J. F. Heigenhauser, and L. L. Spriet, "Human skeletal muscle PDH kinase activity and isoform expression during a 3-day highfat/low-carbohydrate diet," American Journal of PhysiologyEndocrinology and Metabolism, vol. 281, no. 6, pp. E1151-E1158, 2001.

[73] A. Elbrecht, Y. Chen, C. A. Cullinan et al., "Molecular cloning, expression and characterization of human peroxisome proliferator activated receptors $\gamma 1$ and $\gamma 2$," Biochemical and Biophysical Research Communications, vol. 224, no. 2, pp. 431-437, 1996.
[74] L. Fajas, D. Auboeuf, E. Raspé et al., "The organization, promoter analysis, and expression of the human PPAR $\gamma$ gene," The Journal of Biological Chemistry, vol. 272, no. 30, pp. 1877918789, 1997.

[75] B. Desvergne and W. Wahli, "Peroxisome proliferator-activated receptors: nuclear control of metabolism," Endocrine Reviews, vol. 20, no. 5, pp. 649-688, 1999.

[76] S. M. Rangwala and M. A. Lazar, "Peroxisome proliferatoractivated receptor $\gamma$ in diabetes and metabolism," Trends in Pharmacological Sciences, vol. 25, no. 6, pp. 331-336, 2004.

[77] F. Picard and J. Auwerx, "PPAR $\gamma$ and glucose homeostasis," Annual Review of Nutrition, vol. 22, pp. 167-197, 2002.

[78] H.-I. Kim and Y.-H. Ahn, "Role of peroxisome proliferatoractivated receptor- $\gamma$ in the glucose-sensing apparatus of liver and $\beta$-cells," Diabetes, vol. 53, supplement 1, pp. S60-S65, 2004.

[79] N. Wang, G. Yang, Z. Jia et al., "Vascular PPAR $\gamma$ controls circadian variation in blood pressure and heart rate through Bmall," Cell Metabolism, vol. 8, no. 6, pp. 482-491, 2008.

[80] Y. Lecarpentier, V. Claes, and J.-L. Hébert, "PPARs, cardiovascular metabolism, and function: near- or far-from-equilibrium pathways," PPAR Research, vol. 2010, Article ID 783273, 10 pages, 2010.

[81] B. N. Finck, C. Bernal-Mizrachi, D. H. Han et al., "A potential link between muscle peroxisome proliferator- activated receptor- $\alpha$ signaling and obesity-related diabetes," Cell Metabolism, vol. 1, no. 2, pp. 133-144, 2005.

[82] A. Ben-Ze'ev and B. Geiger, "Differential molecular interactions of $\beta$-catenin and plakoglobin in adhesion, signaling and cancer," Current Opinion in Cell Biology, vol. 10, no. 5, pp. 629-639, 1998.

[83] J. Zhurinsky, M. Shtutman, and A. Ben-Ze'ev, "Differential mechanisms of LEF/TCF family-dependent transcriptional activation by $\beta$-catenin and plakoglobin," Molecular and Cellular Biology, vol. 20, no. 12, pp. 4238-4252, 2000.

[84] P. J. Morin, A. B. Sparks, V. Korinek et al., "Activation of $\beta$ catenin-Tcf signaling in colon cancer by mutations in $\beta$-catenin or APC," Science, vol. 275, no. 5307, pp. 1787-1790, 1997.

[85] R. Najdi, R. Holcombe, and M. Waterman, "Wnt signaling and colon carcinogenesis: beyond APC," Journal of Carcinogenesis, vol. 10, article no. 5, 2011.

[86] E. Å. Jansson, A. Are, G. Greicius et al., "The Wnt/ $\beta$-catenin signaling pathway targets PPAR $\gamma$ activity in colon cancer cells," Proceedings of the National Academy of Sciences of the United States of America, vol. 102, no. 5, pp. 1460-1465, 2005.

[87] J.-H. Xiao, C. Ghosn, C. Hinchman et al., "Adenomatous polyposis coli (APC)-independent regulation of $\beta$-catenin degradation via a retinoid X receptor-mediated pathway," Journal of Biological Chemistry, vol. 278, no. 32, pp. 29954-29962, 2003.

[88] P. Sarraf, E. Mueller, W. M. Smith et al., "Loss-of-function mutations in PPAR $\gamma$ associated with human colon cancer," Molecular Cell, vol. 3, no. 6, pp. 799-804, 1999.

[89] G. D. Girnun, W. M. Smith, S. Drori et al., "APC-dependent suppression of colon carcinogenesis by PPAR $\gamma$," Proceedings of the National Academy of Sciences of the United States of America, vol. 99, no. 21, pp. 13771-13776, 2002.

[90] P. Sarraf, E. Mueller, D. Jones et al., "Differentiation and reversal of malignant changes in colon cancer through PPAR $\gamma$," Nature Medicine, vol. 4, no. 9, pp. 1046-1052, 1998.

[91] E. Osawa, A. Nakajima, K. Wada et al., "Peroxisome proliferator-activated receptor $\gamma$ ligands suppress colon carcinogenesis induced by azoxymethane in mice," Gastroenterology, vol. 124, no. 2, pp. 361-367, 2003. 
[92] E. Saez, P. Tontonoz, M. C. Nelson et al., "Activators of the nuclear receptor PPAR $\gamma$ enhance colon polyp formation," Nature Medicine, vol. 4, no. 9, pp. 1058-1061, 1998.

[93] A. M. Lefebvre, I. Chen, P. Desreumaux et al., "Activation of the peroxisome proliferator-activated receptor gamma promotes the development of colon tumors in C57BL/6J-APCMin/+ mice," Nature Medicine, vol. 4, pp. 1053-1057, 1998.

[94] G. T. Robbins and D. Nie, "PPAR gamma, bioactive lipids, and cancer progression," Frontiers in Bioscience, vol. 17, no. 5, pp. 1816-1834, 2012.

[95] L. Gelman, J. N. Feige, and B. Desvergne, "Molecular basis of selective PPAR $\gamma$ modulation for the treatment of Type 2 diabetes," Biochimica et Biophysica Acta, vol. 1771, no. 8, pp. 1094-1107, 2007.

[96] I. Barroso, M. Gurnell, V. E. F. Crowley et al., "Dominant negative mutations in human PPAR $\gamma$ associated with severe insulin resistance, diabetes mellitus and hypertension," Nature, vol. 402, no. 6764, pp. 880-883, 1999.

[97] D. B. Savage, G. D. Tan, C. L. Acerini et al., "Human metabolic syndrome resulting from dominant-negative mutations in the nuclear receptor peroxisome proliferator-activated receptor- $\gamma$," Diabetes, vol. 52, no. 4, pp. 910-917, 2003.

[98] N. Marx, J. Froehlich, L. Siam et al., "Antidiabetic PPAR $\gamma$ activator rosiglitazone reduces MMP-9 serum levels in type 2 diabetic patients with coronary artery disease," Arteriosclerosis, Thrombosis, and Vascular Biology, vol. 23, no. 2, pp. 283-288, 2003.

[99] S. G. Dubois, L. K. Heilbronn, S. R. Smith, J. B. Albu, D. E. Kelley, and E. Ravussin, "Decreased expression of adipogenic genes in obese subjects with type 2 diabetes," Obesity, vol. 14, no. 9, pp. 1543-1552, 2006.

[100] W. Ip, Y.-T. A. Chiang, and T. Jin, “The involvement of the wnt signaling pathway and TCF7L2 in diabetes mellitus: the current understanding, dispute, and perspective," Cell and Bioscience, vol. 2, no. 1, article 28, 2012.

[101] W. Ip, W. Shao, Y.-T. A. Chiang, and T. Jin, "The Wnt signaling pathway effector TCF7L2 is upregulated by insulin and represses hepatic gluconeogenesis," American Journal of Physiology_Endocrinology and Metabolism, vol. 303, no. 9, pp. E1166-E1176, 2012.

[102] R. Saxena, L. Gianniny, N. P. Burtt et al., "Common single nucleotide polymorphisms in TCF7L2 are reproducibly associated with type 2 diabetes and reduce the insulin response to glucose in nondiabetic individuals," Diabetes, vol. 55, no. 10, pp. 2890-2895, 2006.

[103] V. Lyssenko, "The transcription factor 7-like 2 gene and increased risk of type 2 diabetes: an update," Current Opinion in Clinical Nutrition and Metabolic Care, vol. 11, no. 4, pp. 385$392,2008$.

[104] J. C. Florez, "The new type 2 diabetes gene TCF7L2," Current Opinion in Clinical Nutrition and Metabolic Care, vol. 10, no. 4, pp. 391-396, 2007.

[105] K. R. Owen and M. I. McCarthy, "Genetics of type 2 diabetes," Current Opinion in Genetics and Development, vol. 17, no. 3, pp. 239-244, 2007.

[106] M. N. Weedon, “The importance of TCF7L2," Diabetic Medicine, vol. 24, no. 10, pp. 1062-1066, 2007.

[107] T. Jin, "The WNT signalling pathway and diabetes mellitus," Diabetologia, vol. 51, no. 10, pp. 1771-1780, 2008.

[108] T. Fujino, H. Asaba, M.-J. Kang et al., "Low-density lipoprotein receptor-related protein 5 (LRP5) is essential for normal cholesterol metabolism and glucose-induced insulin secretion," Proceedings of the National Academy of Sciences of the United States of America, vol. 100, no. 1, pp. 229-234, 2003.

[109] Z. Ni, Y. Anini, X. Fang, G. Mills, P. L. Brubaker, and T. Jin, "Transcriptional activation of the proglucagon gene by lithium and $\beta$-catenin in intestinal endocrine L cells," The Journal of Biological Chemistry, vol. 278, no. 2, pp. 1380-1387, 2003.

[110] F. Yi, P. L. Brubaker, and T. Jin, “TCF-4 mediates cell typespecific regulation of proglucagon gene expression by $\beta$-catenin and glycogen synthase kinase-3 $\beta$," Journal of Biological Chemistry, vol. 280, no. 2, pp. 1457-1464, 2005.

[111] F. Yi, J. Sun, G. E. Lim, I. G. Fantus, P. L. Brubaker, and T. Jin, "Cross talk between the insulin and Wnt signaling pathways: evidence from intestinal endocrine L cells," Endocrinology, vol. 149, no. 5, pp. 2341-2351, 2008.

[112] A. Kanazawa, S. Tsukada, A. Sekine et al., "Association of the gene encoding wingless-type mammary tumor virus integration-site family member 5B (WNT5B) with type 2 diabetes," American Journal of Human Genetics, vol. 75, no. 5, pp. 832-843, 2004.

[113] P. J. Hey, R. C. J. Twells, M. S. Phillips et al., "Cloning of a novel member of the low-density lipoprotein receptor family," Gene, vol. 216, no. 1, pp. 103-111, 1998.

[114] R. C. J. Twells, C. A. Mein, F. Payne et al., "Linkage and association mapping of the LRP5 locus on chromosome 11q13 in type 1 diabetes," Human Genetics, vol. 113, no. 2, pp. 99-105, 2003.

[115] L. Shu, N. S. Sauter, F. T. Schulthess, A. V. Matveyenko, J. Oberholzer, and K. Maedler, "Transcription factor 7-like 2 regulates $\beta$-cell survival and function in human pancreatic islets," Diabetes, vol. 57, no. 3, pp. 645-653, 2008. 


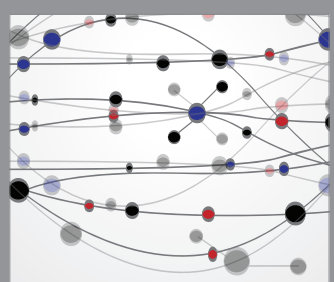

The Scientific World Journal
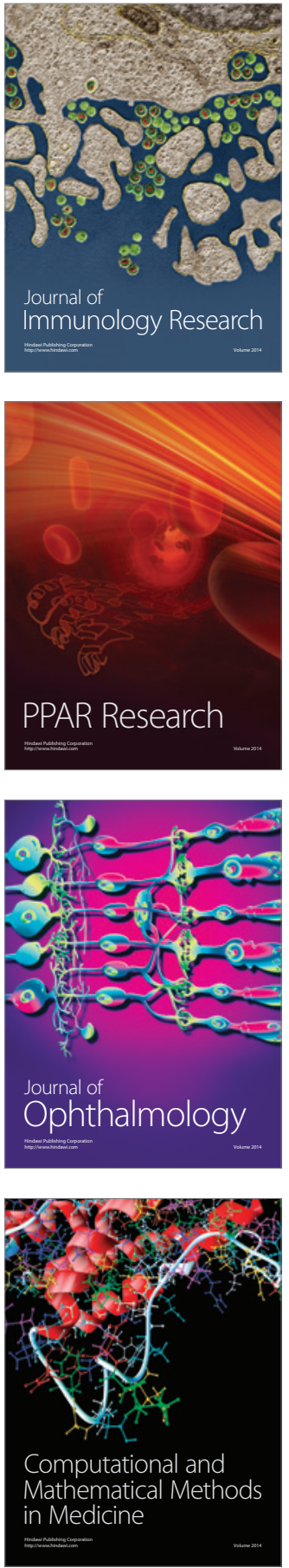

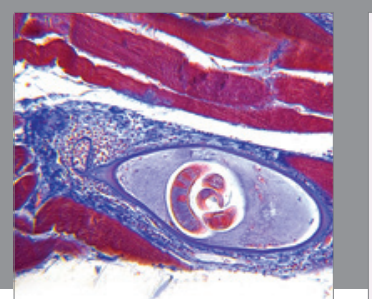

Gastroenterology Research and Practice
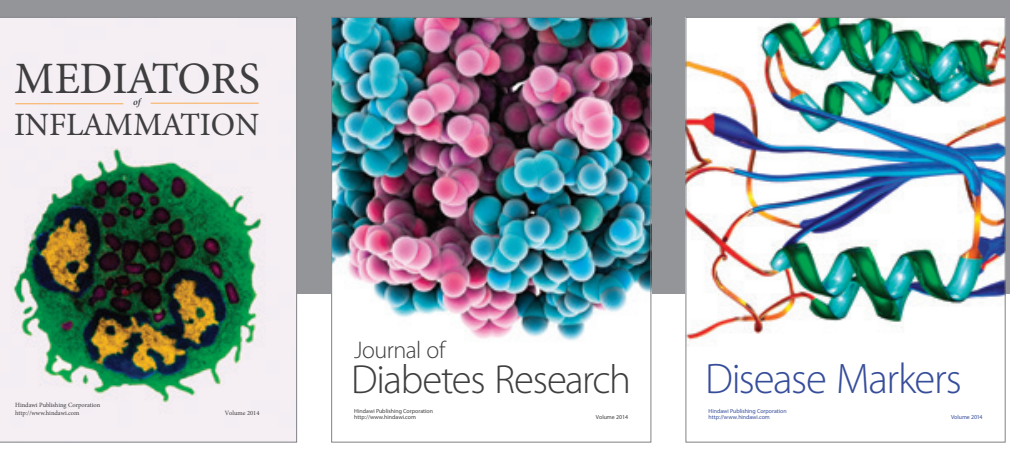

Disease Markers

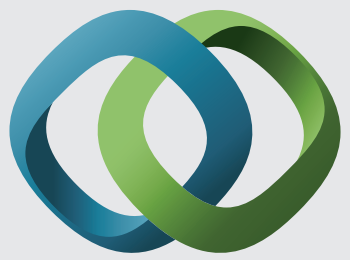

\section{Hindawi}

Submit your manuscripts at

https://www.hindawi.com
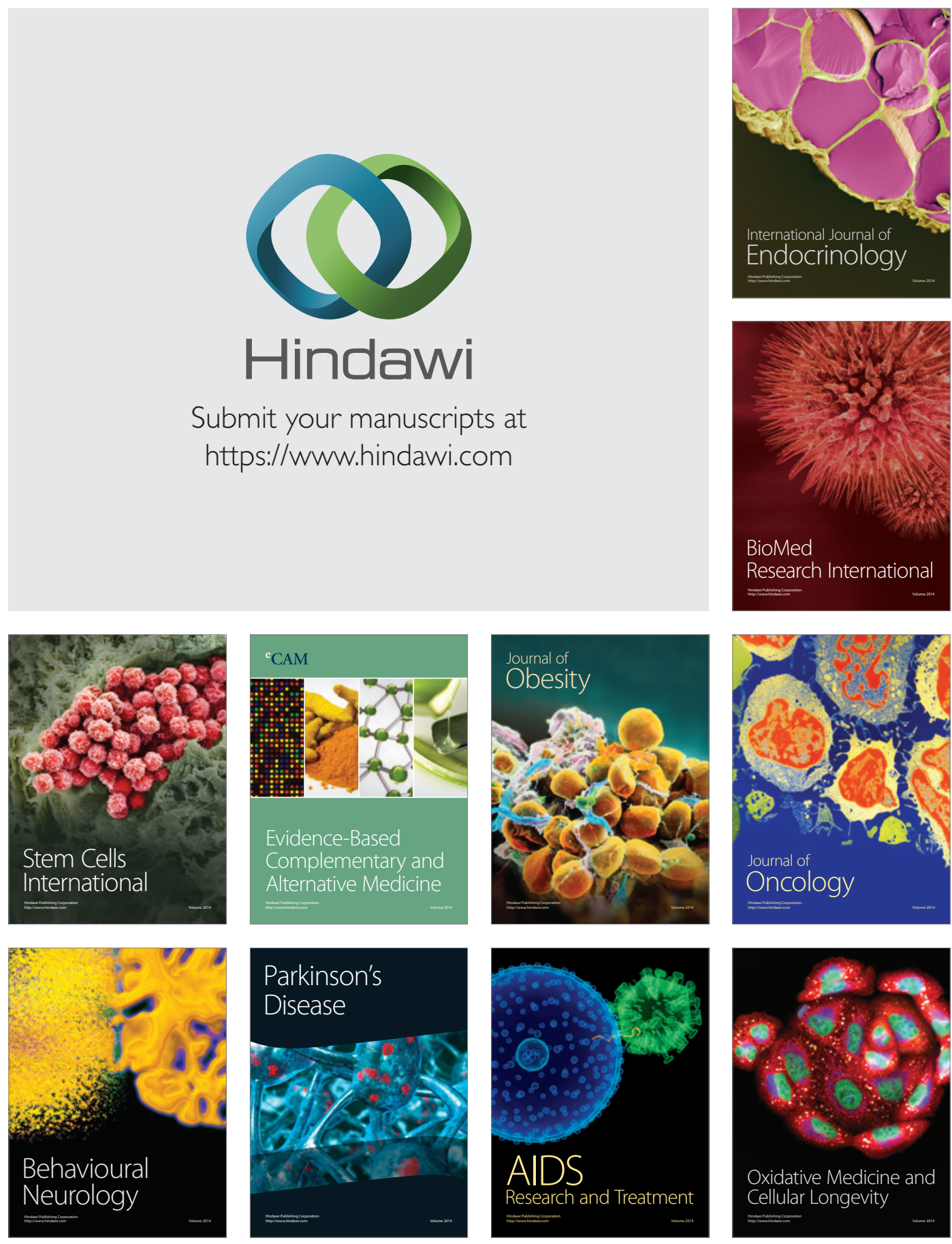